\title{
Analysis by DC-EPG of the resistance to Bemisia tabaci on an Mi-tomato line
}

\author{
Y. X. Jiang*, G. Nombela \& M. Muñiz** \\ Departamento de Protección Vegetal, Centro de Ciencias Medioambientales, CSIC, c/Serrano 115 Dpdo, \\ 28006 Madrid, Spain; ${ }^{*}$ Current address: University of California, Riverside, CA 92521, USA; ${ }^{* *}$ Author for \\ correspondence (E-mail: mmuniz@ccma.csic.es)
}

Accepted: November 30, 2000

Key words: Bemisia tabaci, Mi gene, tomato, EPG, resistance mechanisms, Hemiptera, Aleyrodidae

\begin{abstract}
The tomato $\mathrm{Mi}$ gene confers resistance to nematodes, Meloidogyne spp., and to the potato aphid, Macrosiphum euphorbiae (Thomas). Previous greenhouse choice assays with Bemisia tabaci (Gennadius) showed that tomato commercial varieties carrying this gene had significantly lower values of host suitability and whitefly reproduction than varieties lacking $M i$. This indicated that $M i$, or another gene in its region, could regulate partial resistance. In order to characterise this resistance, probing and feeding behaviour of Bemisia tabaci B-biotype was studied with DC Electrical Penetration Graph (EPG) technique on the near-isogenic tomato lines Moneymaker (without $\mathrm{Mi}$ ) and Motelle (carrying $\mathrm{Mi}$ ). Significant differences $(\mathrm{P}<0.05)$ between tomato lines were found in EPG parameters related to epidermis and/or mesophyll tissues. On Motelle, a lower percentage of whiteflies achieved phloem phase and they made more probes before attaining first phloem phase, had a higher ratio (number of probes before first phloem phase)/(total number of probes), had a longer total duration of non-probing time, and a longer time before making the first intracellular puncture and before making the first phloem phase. In contrast, most of the parameters related to phloem phase were found not to differ significantly between these near-isogenic lines. The behavioural data strongly suggest that the partial resistance in the variety Motelle is due to factors in the epidermis and/or mesophyll that inhibit the whiteflies from reaching phloem sieve elements. However, once the stylets reach a sieve element, whitefly behaviour did not differ between the two varieties. Thus, phloem sap of the two varieties appears to be equally acceptable to the whiteflies. Further studies are necessary to provide a better understanding of these mechanisms of resistance to whiteflies in tomatoes.
\end{abstract}

\section{Introduction}

The sweetpotato whitefly, Bemisia tabaci (Gennadius) is a devastating pest of vegetables, ornamentals, and agronomic crops throughout the tropical and subtropical regions of the world. Losses caused by $B$. tabaci to tomato, Lycopersicon esculentum Mill., are the result of direct feeding damage, deposition of large quantities of honeydew, and transmission of several plant viruses (Moriones et al., 1993; Bedford et al., 1994; Markham et al., 1994). Because of environmental concerns on the use of pesticides in agriculture, alternate means of $B$. tabaci control are being sought. As an alternative approach to chemical control, host plant resistance has been increasingly recognised as being one of the most desirable and economic control tactics in the management of whiteflies.

The $M i$ gene of tomato was reported to confer effective field resistance to three root-knot nematode species, Meloidogyne incognita Chitwood, M. javanica Chitwood and $M$. arenaria Chitwood (Gilber \& McGuire, 1956; Braham \& Winsted, 1957; Roberts \& Thomason, 1986). It also was reported that $M i$ controlled resistance to reproduction of a race and one isolate of another race of $M$. chitwoodi Golden in the greenhouse (Brown et al., 1997). The $M i$ gene was cloned (Milligan et al., 1998) and described as dominant, or semi-dominant in tomato, and was 
introduced into tomato from the wild species $L y$ copersicon peruvianum using embryo rescue of an interspecific cross of this wild species with $L$. esculentum (Smith, 1944). Tomato lines that carried the nematode-resistance gene, $M i$, displayed resistance in the field to the potato aphid Macrosiphum euphorbiae (Thomas). In the greenhouse this insect had significantly higher mortality and lower fecundity on tomato lines carrying- $M i$ than on near isogenic lines lacking$M i$ (Kaloshian et al., 1997). Finally, Mi was reported to confer resistance against the potato aphid (Rossi et al., 1998). Our recent greenhouse choice assays with $B$. tabaci demonstrated that tomato varieties carrying this gene showed significantly lower values of host suitability and whitefly reproduction than varieties lacking Mi (Nombela et al., 2000), indicating that $M i$ or another gene in its region, could regulate partial resistance to whiteflies.

Detailed behavioural studies can play an important role in determining mechanisms of plant resistance to whiteflies. As phloem sap feeders, whiteflies penetrate their mouthparts into the leaf tissue, covering the distance from the epidermis to the phloem vessel intercellularly, and finally feed on substances in the sieve elements (Pollard, 1955). In this way whiteflies can locate possible plant resistance factors at the successive levels of the tissues encountered from the surface to the phloem sieve element. Thus, the study of stylet penetration behaviour can provide clues for determining what kind of resistance mechanisms may be involved. No technique has been more useful in revealing detailed information about stylet penetration behaviour of homopteran insects than the electrical penetration graph (EPG) technique, which was first developed for aphids by McLean \& Kinsey (1964) using an AC circuit and later modified by Tjallingii (1978) using a DC circuit. However, only recently this technique has been used to study the feeding behaviour of adult whiteflies Trialeurodes vaporariorum (Westwood) and Bemisia tabaci (Gennadius) on a DC system (Janssen et al., 1989; Lei et al., 1996, 1998, 1999; Jiang et al., 1999, 2000; Johnson \& Walker, 1999) and for Bemisia argentifolii Bellows \& Perring and Parabemisia myricae (Kuwana) with an AC system (Walker \& Perring, 1994).

Little is known about the mechanisms of plant resistance to whiteflies (Berlinger, 1986). Of special relevance to this, the mechanisms of plant resistance to aphids have been extensively studied by using the EPG technique (Montllor \& Tjallingii, 1989; Kimmins, 1989; Cole et al., 1993; Cole, 1994; Wilkinson
\& Douglas, 1998; Sauge et al., 1998). By analysing 'non-sequential' (van Helden \& Tjallingii, 1993) and 'sequential' parameters obtained from EPG experiments or combined with other analytical methods (Caillaud et al., 1995), EPG data can be used as an indicator for tissue location of plant resistance factors (Tjallingii, 1995). For example, EPG data from a study on lettuce suggest that resistance to the aphid Nasonovia ribisnigri (Mosley) is in the phloem of the resistant variety (van Helden \& Tjallingii,1993). Similarly, behavioural analysis of Aphis gossypii Glover feeding on melon showed that expression of the Vat resistance gene produces alterations of chemical compounds in the phloem of a resistant melon line (Chen et al., 1996). In contrast, EPG analysis of resistance in tomato and sweet pepper against greenhouse whiteflies suggests that resistance is based on factors present in the surface/epidermis and/or in the mesophyll layer of pepper plants (Lei et al., 1999).

The aim of this study was to characterise the mechanisms of the tomato resistance to $B$. tabaci previously observed in a number of $M i$-carrying commercial varieties. Therefore, the probing and feeding behaviour of B. tabaci B-biotype was studied on the two near isogenic tomato lines Moneymaker (without $\mathrm{Mi}$ ) and Motelle (carrying $\mathrm{Mi}$ ) by using DC electrical penetration graphs. Consequently, the possible resistance factors at the successive levels of tissues in tomato plants were located. Moreover, EPG data were compared with the greenhouse choice assays in this paper.

\section{Materials and methods}

Whitefly colony and tomato plants. A Spanish population of B. tabaci, previously identified by Guirao et al. (1997) as B-biotype, was reared on Lycopersicon esculentum Mill. tomato var. Río Fuego at $27: 23{ }^{\circ} \mathrm{C}$ (day:night) and at a photoperiod of L16:D8 h. Plants of the tomato lines Motelle (carrying $M i$ gene) and Moneymaker (without $M i$ gene) were grown in pots in an insect-proof chamber with artificial light at a photoperiod of L16:D8 at $26 \pm 1{ }^{\circ} \mathrm{C}$ and used at 34 true leaf stage as test plants. Moneymaker and Motelle are near-isogenic lines and differ only in the presence of a $650 \mathrm{~kb}$ introgressed region from L. peruvianum containing the $M i$ gene, in chromosome 6 of Motelle. Individual 2-3-day-old female whiteflies were kept at $4{ }^{\circ} \mathrm{C}$ for $5-10 \mathrm{~s}$ and then transferred to a stereo-microscope (Nikon SMZ-2T, Nikon Crop. Tokyo, Japan) and immobilised using a small vac- 
uum pump (Vacuum pump A 3S, Tokyo Rikakikai Co. LTD, Japan). Subsequently, a $10 \mu \mathrm{m}$ gold wire was attached to the dorsum of whiteflies using a small silver paint droplet (solvent: isopropyl alcohol and methyl ethyl ethylketone, Pelco ${ }^{\circledR}$ Coloidal Silver, Ted Pella, Inc., Reeding, CA). After wire attachment, whiteflies were maintained inside a glass Petri dish for about 1-h acclimation and then connected to the amplifier for the test.

$E P G$ recording. The feeding behaviour of $B$. tabaci was electrically monitored using a DC-system with a $10^{9} \mathrm{Ohm}$ input resistance in a Faraday cage (Tjallingii, 1990). A Giga-4 DC-amplifier was connected to a microcomputer using an A/D card (sample rate of the A/D card $=100 \mathrm{~Hz})$ (ACM-12-8, Strawberry Tree, Sunnyvale, CA), as well as a strip-chart recorder (Konik, KNK-801-201, Japan). The output signals were stored using the $A=\mathrm{cm}^{2}$ acquisition software version 1.0 (Febvay, 1994). A wired individual whitefly was connected to the amplifier and placed on the abaxial surface of the fully expanded second leaf of a tomato test plant (leaf turned over and fixed by Parafilm so abaxial surface faced up). The EPG signal was monitored for $6 \mathrm{~h}$ per whitefly. A total of 25 whiteflies on Motelle and 26 on Moneymaker plants were recorded, each whitefly individual was recorded on a single tomato plant.

The analysis of EPG waveforms was carried out using the Macstylet software version 2.0 (Febvay et al., 1996). The following waveforms, partially correlated with behavioural events in greenhouse whiteflies (Janssen et al., 1989) and in B. tabaci (Jiang et al., 1999), were characterised: waveform $C$, intercellular stylet pathway; pd, short intracellular puncture during pathway; waveform $\mathrm{G}$, xylem ingestion; and waveform F, mechanical probing difficulties. Also, waveform $\mathrm{E}(\mathrm{pd})_{1}$, which was correlated with salivation into phloem sieve elements (Jiang et al., 2000), and $\mathrm{E}(\mathrm{pd})_{2}$, being regarded as ingestion from phloem that is comparable to E2 of aphids (Prado \& Tjallingii, 1994) were characterised. EPG parameters were carefully extracted based on previous work on aphids (Tjallingii, 1995; Caillaud et al., 1995), choosing only those parameters that can provide information on locating plant resistance factors in different tissues. Table 1 shows possible plant tissues involved as well as all parameters that were classified into two catalogues: non-phloem phase (including pathway phase and xylem phase) and phloem phase.
Statistical analysis. Comparison of mean EPG parameters from two isogenic tomato lines was performed according to the Mann-Whitney U test using Statview software (Abacus Concepts, 1987). In the case of percentages, the chi-square test was used at 0.05 and 0.001 levels.

\section{Results}

Parameters related to non-phloem phase (including pathway and xylem ingestion phases) (Table 2). A number of EPG parameters related to pathway phase were found to differ significantly between Moneymaker (without $M i$ ) and Motelle (carrying $M i$ ). On Motelle, a lower percentage of whiteflies achieved phloem phase $(\mathrm{P}<0.01)$ and they made more probes before attaining the first phloem phase $(\mathrm{P}<0.05)$, had a higher ratio (number of probes before the 1st phloem phase)/(total number of probes) $(\mathrm{P}<0.01)$, had a longer total duration of non-probing time $(\mathrm{P}<$ 0.05 ), and a longer time before making the 1 st intracellular puncture $(\mathrm{P}<0.05)$ and the 1 st phloem phase $(\mathrm{P}<0.01)$. However, parameters more directly related with surface factors (parameters 1,2 and 3) as well as those related to waveforms $\mathrm{G}$ (xylem ingestion) and F (mechanical difficulty) did not differ significantly between the two tomato lines (Table 2).

Parameters related to phloem phase (Table 3). Except for the time that whiteflies took from start of the $6 \mathrm{~h}$ experiment to the 1 st sustained phloem ingestion $(\mathrm{P}<0.01)$ and the percentage of whiteflies showing sustained ingestion $(\mathrm{P}<0.05)$, most of the parameters related to phloem phase were found not to differ significantly between these two near-isogenic tomato lines. Moreover, the total time that whiteflies spent ingesting phloem sap was almost the same in Motelle as that in Moneymaker. Similarly, the numbers of E(pd) and $\mathrm{E}(\mathrm{pd})_{2}$ were almost the same in both tomato line (parameters 20, 23, Table 3.).

\section{Discussion and conclusions}

Comparison of EPG profile with greenhouse preference study. Our previous preference study with the B-biotype of $B$. tabaci showed that significantly fewer Motelle plants than Moneymaker plants were infested by females in a greenhouse choice test. Also, the daily 
Table 1. EPG parameters and possible relations to resistance factors in specific plant tissue

\begin{tabular}{|c|c|}
\hline EPG parameters & Tissue(s)/factors involved \\
\hline \multicolumn{2}{|l|}{ Non-phloem parameters } \\
\hline 1. Time to the first probe & surface factors \\
\hline 2. Duration of 1 st probe & surface factors + epidermis/mesophyll \\
\hline 3. Total number of probes & surface factors + all plant tissues \\
\hline 4. Number of probes made before attaining the first phloem phase (1st $\mathrm{E}(\mathrm{pd}))$ & epidermis, mesophyll and other parenchyma \\
\hline 5. Ratio of probes before $1 \mathrm{st} \mathrm{E}(\mathrm{pd}) /$ total number of probes & epidermis, mesophyll and other parenchyma \\
\hline 6. Total duration of non-probing time & all plants tissues except phloem \\
\hline 7. Total duration of $\mathrm{F}$ & all plant tissues except phloem \\
\hline 8. Total duration of $\mathrm{G}$ & xylem factors \\
\hline $\begin{array}{l}\text { 9. Time whitefly took to make its first intracellular puncture (1st pd) from the start of the } \\
6 \mathrm{~h} \text { experiment }(\mathrm{min})\end{array}$ & all plant tissues except phloem \\
\hline 10. Time whitefly took to the $1 \mathrm{st} \mathrm{E}(\mathrm{pd})$ from the start & all plants tissues except phloem \\
\hline 11. Time whitefly took to $1 \mathrm{st} \mathrm{E}(\mathrm{pd})$ within probe & all plants tissues except phloem \\
\hline 12. $\%$ of whitefly reaching the phloem phase & epidermis, mesophyll and other parenchyma \\
\hline \multicolumn{2}{|l|}{ Phloem parameters } \\
\hline $\begin{array}{l}\text { 13. Duration between time to the } 1 \mathrm{st} \mathrm{E}(\mathrm{pd}) \text { and time to the first sustained ingestion (1st } \\
\mathrm{SI})\left(\mathrm{E}(\mathrm{pd})_{2}>15 \mathrm{~min}\right)\end{array}$ & vascular tissue and sieve elements (initial factors) \\
\hline 14. Time whitefly took to 1 st SI from start & all plant tissues \\
\hline 15. $\%$ of time whitefly spent in $\mathrm{E}(\mathrm{pd})_{2}$ after the 1 st phloem phase & phloem factors \\
\hline 16. Duration of $\mathrm{E}(\mathrm{pd})_{1}$ preceding the first $\mathrm{E}(\mathrm{pd})_{2}>15 \mathrm{~min}$ & phloem factors \\
\hline 17. Duration of $\mathrm{E}(\mathrm{pd})_{2}$ after the $1 \mathrm{st} \mathrm{SI}$ & phloem factors \\
\hline 18. Total duration of $E(\mathrm{pd})_{1}$ & phloem factors \\
\hline 19. Mean duration of $\mathrm{E}(\mathrm{pd})_{1}$ & phloem factors \\
\hline 20. No. of $\mathrm{E}(\mathrm{pd})_{1}$ & phloem factors \\
\hline 21. Total duration of $\mathrm{E}(\mathrm{pd})_{2}$ & phloem factors \\
\hline 22. Mean duration of $\mathrm{E}(\mathrm{pd})_{2}$ & phloem factors \\
\hline 23. No. of $\mathrm{E}(\mathrm{pd})_{2}$ & phloem factors \\
\hline 24. $\%$ of whiteflies showing sustained ingestion $(\mathrm{E}(\mathrm{pd})>15 \mathrm{~min}$. & all plant tissues \\
\hline
\end{tabular}

Table 2. Comparison of EPG parameters of B-biotype of B. tabaci on two isogenic tomato lines during 6-h recordings

\begin{tabular}{|c|c|c|}
\hline EPG parameters & $\begin{array}{l}\text { Moneymaker } \\
\text { Mean } \pm \text { SE }(n)\end{array}$ & $\begin{array}{l}\text { Motelle } \\
\text { Mean } \pm \operatorname{SE}(n)\end{array}$ \\
\hline 1. Time to the first probe (1st probe) $(\mathrm{s})$ & $39.09 \pm 14.94(25)$ & $61.68 \pm 25.76(26) \mathrm{Ns}$ \\
\hline 2. Duration of 1 st probe $(\mathrm{s})$ & $89.48 \pm 24.96(25)$ & $99.78 \pm 31.11(26) \mathrm{Ns}$ \\
\hline 3. Total number of probes & $44.36 \pm 5.05(25)$ & $57.23 \pm 8.38(26) \mathrm{Ns}$ \\
\hline 4. Number of probes made before attaining the first phloem phase (1st E(pd) & $27.08 \pm 3.65(25)$ & $53.00 \pm 8.87(26)^{*}$ \\
\hline 5. Ratio of probe before $1 \mathrm{st} \mathrm{E}(\mathrm{pd}) /$ total number of probes & $0.65 \pm 0.06(25)$ & $0.86 \pm 0.05(26)^{* *}$ \\
\hline 6. Total duration of non-probe time ( $\mathrm{min})$ & $65.81 \pm 7.95(25)$ & $100.39 \pm 11.50(26)^{*}$ \\
\hline 7. Total duration of $\mathrm{F}$ (min) & $21.12 \pm 4.00(12)$ & $32.54 \pm 6.65(19) \mathrm{Ns}$ \\
\hline 8. Total duration of $\mathrm{G}(\mathrm{min})$ & $20.31 \pm 3.25(9)$ & $42.88 \pm 15.62(14) \mathrm{Ns}$ \\
\hline $\begin{array}{l}\text { 9. Time whitefly took to make its first intracellular puncture (1st pd) from the start of the } 6 \mathrm{~h} \\
\text { experiment (min) }\end{array}$ & $94.31 \pm 12.44(24)$ & $154.38 \pm 20.32(25)^{*}$ \\
\hline 10. Time whitefly took to the $1 \mathrm{st} \mathrm{E}(\mathrm{pd})$ from the start (min) & $163.25 \pm 20.01(25)$ & $272.16 \pm 22.82(26)^{* *}$ \\
\hline 11. Time whitefly took to $1 \mathrm{st} \mathrm{E}(\mathrm{pd})$ within probe ( $\mathrm{min}$ ) & $21.19 \pm 2.28(22)$ & $38.97 \pm 7.15(13) \mathrm{Ns}$ \\
\hline 12. $\%$ of whitefly reaching the phloem phase & 88.00 & 50.00 \\
\hline
\end{tabular}

Significant differences were compared at 0.05 and 0.01 level according to Mann-Whitney U test (Stateview, Abacus Concepts, 1987). In the case of Percentage or ratio, a chi-square test was used at 0.05 and 0.01 levels. Ns, no significant differences $(\mathrm{P}>$ $0.05),{ }^{*} \mathrm{P}<0.05$ and ${ }^{* *} \mathrm{P}<0.01$. 
Table 3. Comparison of EPG parameters of B-biotype of B. tabaci on two isogenic tomato lines during 6-h recordings

\begin{tabular}{|c|c|c|}
\hline EPG parameters & $\begin{array}{l}\text { Moneymaker } \\
\text { Mean } \pm \text { SE }(n)\end{array}$ & $\begin{array}{l}\text { Motelle } \\
\text { Mean } \pm \text { SE }(n)\end{array}$ \\
\hline $\begin{array}{l}\text { 13. Duration between time to the } 1 \mathrm{st} \mathrm{E}(\mathrm{pd}) \text { and time to the first sustained ingestion (1st SI) } \\
\left(\mathrm{E}(\mathrm{pd})_{2}>15 \mathrm{~min}\right)(\mathrm{min})\end{array}$ & $35.99 \pm 17.79(19)$ & $11.34 \pm 9.72(11) \mathrm{Ns}$ \\
\hline 14. Time whitefly took to $1 \mathrm{st}$ SI from the start of the $6 \mathrm{~h}$ experiment (min) & $188.62 \pm 21.12(25)$ & $277.79 \pm 21.45(26)^{* *}$ \\
\hline 15. $\%$ of time whitefly spent in $\mathrm{E}(\mathrm{pd})_{2}$ after the 1 st phloem phase & $51.96 \pm 28.31(21)$ & $62.4 \pm 35.35(13) \mathrm{Ns}$ \\
\hline 16. Duration of $\mathrm{E}(\mathrm{pd})_{1}$ before $\mathrm{E}(\mathrm{pd})_{2}$ in first or in any $\mathrm{E}(\mathrm{pd})_{2}>15 \mathrm{~min}(\mathrm{~min})$ & $3.17 \pm 0.72(22)$ & $1.63 \pm 0.43(13) \mathrm{Ns}$ \\
\hline 17. Duration of $\mathrm{E}(\mathrm{pd})_{2}$ after the $1 \mathrm{st} \mathrm{SI}(\mathrm{min})$ & $29.35 \pm 9.18(22)$ & $13.39 \pm 7.73(13) \mathrm{Ns}$ \\
\hline 18. Total duration of $\mathrm{E}(\mathrm{pd})_{1}(\mathrm{~min})$ & $5.85 \pm 1.09(22)$ & $3.05 \pm 0.87(13) \mathrm{Ns}$ \\
\hline 19. Mean duration of $\mathrm{E}(\mathrm{pd})_{1}(\mathrm{~min})$ & $2.73 \pm 0.48(22)$ & $1.67 \pm 0.44(13) \mathrm{Ns}$ \\
\hline 20. No. of $\mathrm{E}(\mathrm{pd})_{1}$ & $2.09 \pm 0.24(22)$ & $2.08 \pm 0.50(13) \mathrm{Ns}$ \\
\hline 21. Total duration of $\mathrm{E}(\mathrm{pd})_{2}(\mathrm{~min})$ & $106.44 \pm 17.55(21)$ & $105.10 \pm 24.00(13) \mathrm{Ns}$ \\
\hline 22. Mean duration of $\mathrm{E}(\mathrm{pd})_{2}(\mathrm{~min})$ & $64.88 \pm 14.63(21)$ & $84.41 \pm 25.14(13) \mathrm{Ns}$ \\
\hline 23. No. of $\mathrm{E}(\mathrm{pd})_{2}$ & $1.90 \pm 0.25(21)$ & $1.69 \pm 0.33(13) \mathrm{Ns}$ \\
\hline 24. $\%$ of whiteflies showing sustained ingestion $(\mathrm{E}(\mathrm{pd})>15 \mathrm{~min})$ & $76.00(19 / 25)$ & $42.30(11 / 26)^{*}$ \\
\hline
\end{tabular}

Significant differences were compared at 0.05 and 0.01 levels according to Mann-Whitney U test (Stateview, Abacus Concepts, 1987). In the case of percentage, a chi-square test was used at 0.05 level. Ns, no significant differences $(\mathrm{P}>0.05),{ }^{*} \mathrm{P}$ $<0.05$ and ${ }^{* *} \mathrm{P}<0.01$.

number of females recorded on Motelle was significant less than on Moneymaker (Nombela et al., 2000). On the same two isogenic tomato lines, the EPGs now revealed that a significantly lower percentage of female whiteflies reached phloem on Motelle (50\%) compared to Moneymaker (88\%) within $6 \mathrm{~h}$ (Table 2). Also, a lower number of whiteflies in Motelle (11 out of 26) were able to show sustained ingestion from phloem than on Moneymaker (19 out of 25). This indicates that Motelle plants could drastically reduce the infestation rate and decrease the number of settling adult whiteflies, in agreement with the preference study, and further supports the fact that tested tomato lines carrying the $M i$ gene, display resistance to the B-biotype of B. tabaci.

Possible location of resistant factors at tissue levels. The probing and feeding behaviour performance of whiteflies on the two isogenic tomato cultivars provide invaluable clues for understanding the mechanisms of plant resistance at tissue levels. As mentioned earlier, the whole process of whitefly probing starts with labial contact with the plant surface, followed by insertion of its stylets through successive tissue layers between the epidermis and phloem and, eventually targets on the sieve element of phloem. Therefore, plant tissue factors can play various roles in the initiation, maintenance, and cessation of each subsequent event in the probing process, especially the first phloem phase contact by whiteflies (Lei et al., 1999).
At the level of the surfacelepidermis and/or mesophyll layers. On Motelle, whiteflies showed more probes before attaining the first phloem phase (parameter 4) and time whitefly took to the first phloem phase from the start (parameter 10) when compared with Moneymaker. The point that all these activities occurred before the first phloem contact, strongly suggests that the resistance factors are present on the surface/epidermis and/or mesophyll tissue layers in Motelle plants. Additionally, parameter 6 (total duration of non-probing time) also supports this point, i.e., whiteflies spent more time on non-probing activities (walking or resting), on Motelle than on Moneymaker, clearly indicating, again, a negative effect of the first encountered tissues to whitefly feeding on Motelle plants. Besides, detailed comparison of the percentage of short probes (less than $3 \mathrm{~min}$ ) before the first phloem phase on Motelle (95\%), compared to that on Moneymaker (85\%) (not shown in the Tables), suggests that the plant epidermis might play an important role in Motelle resistance to whiteflies. Our closeup video observations, combined with stylet cutting, proved that whiteflies do not penetrate deeper than the epidermis in such a short time (Y. X. Jiang, unpublished). However, parameters more directly related with surface factors (parameters 1, 2 and 3) did not differ significantly between the two tomato lines (Table 2), which might indicate that these surface factors do not play a major role in the resistance, although the surface and epidemis factors cannot be separated completely based on EPG recordings. In addtion, the role of resistance factors in mesophyll and non-vascular 
tissues cannot be ignored as indicated by parameter 10: the time whiteflies took to reach the first phloem phase within a probe in Motelle $(38.97 \mathrm{~m})$ was much longer than that in Moneymaker $(21.19 \mathrm{~m})$.

At the level of phloem tissue. In an EPG study, Gabrys et al. (1997) reported that less preferred plant parts (Sinapis alba) had deterrent effects at epidermal/mesophyll levels to Brevicoryne brassicae. Apart from that, repetitive failures to start ingestion, and reduced phloem sap ingestion were often typical features associated with resistance as reported in EPG studies performed on aphids/plant combinations (Campbell et al., 1982; van Helden \& Tjallingii, 1993; Cole, 1994; Caillaud et al., 1995; Sauge et al., 1998; Kaloshian et al., 2000). However, the feeding and probing profile of whiteflies from our data on the two isogenic tomato lines revealed a drastically different picture than these aphids, i.e., most of the EPG parameters related to phloem phase did not differ significantly. Specifically, whiteflies spent a similar amount of time ingesting from phloem (duration of $\mathrm{E}(\mathrm{pd})_{2}$, parameter 21, Table 3) in Motelle and Moneymaker, which strongly indicates that the acceptability of phloem sap is rather similar. Also, no significant differences were found in the duration between time to the first phloem phase and time to the first sustained ingestion (parameter 13), percentage of the time whiteflies spent on $\mathrm{E}(\mathrm{pd})_{2}$ after the $1 \mathrm{st}$ phloem phase (parameter 15) and duration of $\mathrm{E}(\mathrm{pd})_{2}$ after the first sustained ingestion (parameter 17) between Motelle and Moneymaker, again indicating that there are no differences in factors in phloem sap between the two isogenic lines that affected whitefly feeding behaviour on the short term, or long term. Evidence from qualitative analysis of honeydew of potato aphids feeding on tomatoes showed that some aphids ingest fluids from resistant tomato plants (with $M i$ gene) although significant reductions in honeydew production occurred in resistant plants (Kaloshian et al., 1997). A possible inference is that the aphids also encountered difficulties going through successive tissue layers (surface, epidermis and mesophyll) and had a low success rate reaching the phloem in the resistant variety, and thus, the delayed phloem ingestion caused less honeydew on $M i$ plants. However, whiteflies spent similar phloem sap ingestion times in resistant plants as in susceptible plants, once their stylets reached the phloem.

Interestingly, two exceptional parameters associated with phloem phase were found to differ sub- stantially on the two isogenic tomato lines: time that whiteflies took from start to the first sustained phloem ingestion (parameter 14) and percentage of whiteflies showing sustained ingestion (parameter 24). A closer look at these two parameters revealed that all nonphloem phase factors rather than only phloem factors are actually involved. Indeed, the whitefly's stylets should go through the epidermis and mesophyll tissues before it eventually reaches the phloem and the whitefly shows sustained ingestion. Based on these data, although the role of initial resistance factors in phloem cannot be completely excluded, they probably do not play a major role in Motelle resistance to whiteflies.

Possible mechanisms of this tomato resistance. Resistance to nematodes Meloidogyne spp., conferred by Mi gene to tomato plants, is characterised by a localised region of necrotic plant cells (hypersensitive response), around the head of the invading nematode (Dropkin, 1969; Ho et al., 1992). The mechanisms of Mi resistance to potato aphid, M. euphorbiae, which drastically reduce longevity and fecundity, and alter feeding behaviour, are still unknown (Rossi et al., 1998). Our previous assays (Nombela et al., 2000) suggested the existence of a partial resistance against Bemisia in Mi-carrying tomato varieties when compared to varieties lacking $M i$, although it is not demonstrated so far whether such a resistance is regulated by $M i$ or by another gene closely linked to it. The present EPG data confirm this resistance and demonstrate that resistance factors in Motelle are detected by $B$. tabaci early during the stylet penetration pathway, indicating that these factors might be present in the plant epidermis and/or mesophyll layers. Although aphids, whiteflies, and nematodes belong to different taxa, they do have some common feeding features, i.e. they penetrate their hosts intercellularly and eventually their stylets terminate at the phloem. Thus, it is likely that these organisms share the same recognition mechanisms in tomato, probably regulated by genefor-gene interactions. A hypothesis for these common resistance mechanisms is that the recognition and initiation of a signal transduction cascade leading to resistance is triggered when aphids, whiteflies, or nematodes start penetrating into the tomato cells located on surface/epidermis and/or mesophyll tissues. This hypothesis needs to be proved by more experiments in the future. Therefore, more detailed studies including histochemical and molecular methods are necessary to provide a better understanding of these mechanisms of resistance in commercial tomato varieties. 


\section{Acknowledgements}

This study was funded by the Dirección General de Investigación Científica y Técnica of the Ministerio de Educación y Ciencia of Spain and from the Comisión Interministerial de Ciencia y Tecnología of Spain, Plan Nacional de I+D, Project AGF97-1143. We deeply thank Greg Walker (University of California, Riverside) for critically reviewing the manuscript. In addition, we thank Dr J. Cuartero (Consejo Superior de Investigaciones Científicas, Málaga) for providing the tomato seeds and information on them. We are grateful to Dr A. Fereres (Consejo Superior de Investigaciones Científicas, Madrid) for providing DC-EPG recording system and laboratory space.

\section{References}

Abacus Concepts, 1987. Statview II. Abacus Concepts, Berkeley, CA.

Bedford, I. D., M. Pinner, S. Liu \& P. G. Markham, 1994. Bemisia tabaci - potential infestation, phytotoxicity and virus transmission within European agriculture. Proceedings of the Brighton Crop Protection Conference: Pests and Diseases 3. The British Crop Protection Council, Farnham, UK., pp. 911-916.

Berlinger, M. J., 1986. Host plant resistance to Bemisia tabaci. Agriculture Ecosystem Environment 17: 69-82.

Braham, W. S. \& N. N. Winstead, 1957. Inheritance of resistance to root-knot nematodes in tomatoes. Proceedings of the American Society of Horticultural Sciences 69: 372 .

Brown, C. R., H. Mojtahedi, G. S. Santo \& V. M. Williamson, 1997. Effect of the $M i$ gene in tomato on reproductive factors of Meloidogyne chitwoodi and M. hapla. Journal of Nematology 29: 416-419.

Caillaud, C. M., J. P. Di Pietro, B. Chaubet \& J. S. Pierre, 1995. Application of discriminate analysis to electrical penetration graphs of the aphid Sitobion avenae feeding on resistant and susceptible wheat. Journal of Applied Entomology 119: 103-106.

Campbell, B. C., D. L. McLean, M. G. Kinsey, K. C. Jones \& D. L. Dreyer, 1982. Probing behavior of the green bug (Schizaphis graminum, biotype C) on resistant and susceptible varieties of sorghum. Entomologia Experimentalis et Applicata 31: 140-146.

Chen, J. Q., B. Delobel, Y. Rahbé \& N. Sauvion, 1996. Biological and chemical characteristics of a genetic resistance of melon to the melon aphid. Entomologia Experimentalis et Applicata 80: 250-253.

Cole, R. A., 1994. Locating a resistance mechanism to the cabbage aphid in two wild Brassicas. Entomologia Experimentalis et Applicata 71: 23-31.

Cole, R. A., W. E. Riggall \& A. Morgan, 1993. Electronically monitored feeding behavior of the lettuce root aphid (Pemphigus bursarius) on resistant and susceptible lettuce varieties. Entomologia Experimentalis et Applicata 68: 179-186.

Dropkin, V. H., 1969. The necrotic reaction of tomatoes and other hosts resistant to Meloidogyne: reversal by temperature. Phytopatholgy: 59: 1632-1637.
Febvay, G., 1994. $\mathrm{A}=\mathrm{cm}^{2}$, a binary acquisition software for use with the Strawberry Tree ACM2-12 A/D card. Institut National des Sciences Appliquées, Lyon.

Febvay, G., Y. Rahbé \& M. van Helden, 1996. Macstylet, software to analyze electrical penetration graph data on the Macintosh. Entomologia Experimentalis et Applicata 80: 105-108.

Gabrys, B., W. F. Tjallingii \& T. A. van Beek, 1997. Analysis of EPG recorded probing by cabbage aphid on host plant parts with different glucosinolate contents. Journal of Chemical Ecology 23: $1661-1674$.

Gilber, J. C. \& D. C., McGuire, 1956. Inheritance of resistance to severe root-knot from Meloidogyne incognita in commercial-type tomatoes. Proceedings of the American Society of Horticultural Sciences 63: 437.

Guirao, P., F. Beitia \& J. L. Cenis, 1997. Biotype determination of Spanish population of Bemisia tabaci (Homoptera: Aleyrodidae). Bulletin of Entomological Research 87: 587-593.

Helden, M. van \& W. F. Tjallingii, 1993. Tissue localization of lettuce resistance to the aphid Nasonovia ribisnigri using electrical penetration graphs. Entomologia Experimentalis et Applicata 68: 269-278.

Ho, J. Y., R. Weide, H. Ma, M. F. van Wordragen, K. N. Lambert, M. Koornneef, P. Zabel \& V. M. Williamson, 1992. The rootknot nematode resistance gene $(\mathrm{Mi})$ in tomato: Construction of a molecular linkage map and identification of dominant cDNA markers in resistant genotypes. Plant Journal 2: 971-982.

Janssen, J. A. M., W. F. Tjallingii \& J. C. van Lenteren, 1989. Electrical recording and ultrastructure of stylet penetration by the greenhouse whitefly. Entomologia Experimentalis et Applicata 52: 69-81.

Jiang, Y. X., H. Lei, J. L. Collar, B. Martin, M. Muñiz \& A. Fereres, 1999. Probing and feeding behavior of two distinct biotypes of Bemisia tabaci (Homoptera: Aleyrodidae) on tomato plants. Journal of Economic Entomology 92: 357-366.

Jiang, Y. X., C. de Blas, L. Barrios \& A. Fereres, 2000. Correlation between whitefly feeding behavior and TYLCV transmission. Annals of the Entomological Society of America 93: 573-579.

Johnson, D. D. \& G. P. Walker, 1999. Intracellular punctures by the adult whitefly Bemisia argentifolii on DC and AC electronic feeding monitors. Entomologia Experimentalis et Applicata 92: 257-270.

Kaloshian, I., M. G. Kinsey, D. E. Ullman \& V. M. Williamson, 1997. The impact of Meul-mediated resistance in tomato on longevity, fecundity and behavior of the potato aphid, Macrosiphum euphorbiae. Entomologia Experimentalis et Applicata 83: 181-187.

Kaloshian, I., M. G. Kinsey, V. M. Williamson \& D. E. Ullman, 2000. Mi-mediated resistance against the potato aphid Macrosiphum euphorbiae (Hemiptera: Aphididae) limits sieve element ingestion. Environmental Entomology 29: 690-695.

Kimmins, F. M., 1989. Electrical penetration graphs from Niloparvata lugens on resistant and susceptible rice varieties. Entomologia Experimentalis et Applicata 50: 69-79.

Lei, H., W. F. Tjallingii, J. C. van Lenteren \& R. M. Xu, 1996. Stylet penetration by larvae of the greenhouse whitefly on cucumber. Entomologia Experimentalis et Applicata 79: 77-84.

Lei, H., W. F. Tjallingii \& J. C. van Lenteren, 1998. Probing and feeding characteristics of the greenhouse whitefly in association with host-plant acceptance and whitefly strains. Entomologia Experimentalis et Applicata 88: 73-80.

Lei, H., J. C. van Lenteren \& W. F. Tjallingii, 1999. Analysis of resistance in tomato and sweet pepper against the greenhouse whitefly using electrically monitored and visually observed 
probing and feeding behavior. Entomologia Experimentalis et Applicata 92: 299-309.

Markham, P. G., I. D. Bedford, S. Liu \& S. P. Marion, 1994. The transmission of geminiviruses by Bemisia tabaci. Pesticide Science 42: 123-128.

McLean, D. L. \& M. G. Kinsey, 1964. A technique for electronically recording aphid feeding and salivation. Nature 202: 1358-1359.

Milligan, S. B., J. Bodeau, J. Yaghoobi, I. Kaloshian, P. Zabel \& V. M. Williamson, 1998. The root knot nematode resistance gene $M i$ from tomato is a member of the leucine zipper, nucleotide binding, leucine-rich repeat family of plant genes. The Plant Cell 10: $1307-1319$.

Montllor, C. B. \& W. F. Tjallingii, 1989. Stylet penetration by two aphid species on susceptible and resistant lettuce. Entomologia Experimentalis et Applicata 52: 103-111.

Moriones, E., J. Arno, G. P. Accotto, E. Noris \& L. Cavallarin, 1993. First report of Tomato yellow leaf curl virus in Spain. Plant Disease 77: 953.

Nombela, G., F. Beitia \& M. Muñiz, 2000. Variation in tomato host response to Bemisia tabaci (Hemiptera: Aleyrodidae) in relation to acyl sugar content and presence of the nematode and potato aphid resistance gene Mi. Bulletin of Entomological Research 90: $161-167$.

Pollard, D. G., 1955. Feeding habits of the cotton whitefly, Bemisia tabaci Genn. (Homoptera: Aleyrodidae). Annals of Applied Biology 43: 664-671.

Prado, E. \& W. F. Tjallingii, 1994. Aphid activities during sieve element punctures. Entomologia Experimentalis et Applicata 72: 157-165.

Roberts, P. A. \& I. J. Thomason, 1986. Variability in reproduction of isolates of Meloidogyne incognita and M. javanica on resistant tomato genotypes. Plant Disease 70: 547-551.
Rossi, M., F. L. Goggin, S. B. Milligan, I. Kaloshian, D. E. Ullman $\&$ V. M. Williamson, 1998. The nematode resistance gene $M i$ of tomato confers resistance against the potato aphid. Proceedings of the National Academy of Sciences, USA 95: 9750-9754.

Sauge, M. H., J. Kervella \& Y. Rahbé, 1998. Probing behavior of the green peach aphid Myzus persicae on resistant prunnus genotypes. Entomologia Experimentalis et Applicata 89: 223-232.

Smith, P. G., 1944. Embryo culture of a tomato species hybrid. Proceedings of the American Society of Horticultural Sciences 44: 413-416.

Tjallingii, W. F., 1978. Electronic recording of penetration behavior by aphids. Entomologia Experimentalis et Applicata 24: 721730.

Tjallingii, W. F., 1990. Continuous recording of stylet penetration activities by aphids. In: R. K. Campbell \& R. D. Eikenbary (eds), Aphid-Plant Genotype Interactions. Elsevier, Amsterdam, pp. 89-99.

Tjallingii, W. F., 1995. Aphid-plant interactions: what goes on in the depth of the tissues ?. Proceedings of Experimental and Applied Entomology 6: 163-169.

Walker, G. P. \& T. M. Perring, 1994. Feeding and oviposition behavior of whiteflies (Homoptera: Aleyrodiae) interpreted from AC electronic feeding monitor waveforms. Annals of the Entomological Society of America 87: 363-374.

Wilkinson, T. L. \& A. E. Douglas, 1998. Plant penetration by pea aphids (Acyrthosiphon pisum) of different plant range. Entomologia Experimentalis et Applicata 87: 43-50. 